\title{
Some Strategies for Sustaining a Walking Routine: Insights From Experienced Walkers
}

\begin{abstract}
Jason Duvall and Raymond De Young
Background: This study explores the strategies that experienced walkers felt were most useful for sustaining outdoor walking routines. To investigate this issue, a survey-based instrument was used in combination with a Conceptual Content Cognitive Mapping (3CM) exercise. Methods: Seventy-one experienced walkers were asked to complete the $3 \mathrm{CM}$ exercise to explore the strategies that have helped them regularly walk outdoors. After 1 week these same individuals received a survey investigating these same issues as well as demographics and physical activity participation. Results: There was general agreement between 3CM and survey data with respect to the strategies used by experienced walkers. The most highly endorsed strategies involved using health goals and supportive walking environments. Survey results also revealed that those more likely to endorse the use of social support took fewer walks per week, but engaged in more nonwalking related physical activity. Conclusions: Overall, the findings suggest that experienced walkers use a variety of strategies. Strategies such as focusing of the positive health outcomes, using attractive natural settings, and developing realistic action plans appeared to be the most useful. These results also indicate the $3 \mathrm{CM}$ technique may be an effective way to explore beliefs and motivations regarding physical activity.
\end{abstract}

Keywords: behavioral strategies, motivation, Conceptual Content Cognitive Mapping (3CM)

During the last several decades the problem of obesity and inactivity has become a major public health concern. ${ }^{1-4}$ Fortunately, research indicates that encouraging individuals to walk for as little as 30 minutes each day may be an effective way to address this growing public health crisis. ${ }^{5}$ Getting people to adopt a regular walking routine, however, has proven to be an extremely difficult task. As a result, many researchers and public health practitioners have focused their attention on identifying and understanding how various psychological, social, situational, and environmental factors impact an individual's physical activity participation. While this effort has led to a much richer and more comprehensive understanding of the forces that influence walking, translating these insights into concrete strategies which can be used to help individuals adopt and maintain a regular walking routine has remained a challenge. ${ }^{6,7}$

The research presented here is part of an ongoing effort to deal with this challenge by investigating how individuals naturally cope with the variety of problems associated with maintaining physical activity routines. With that objective in mind, this study:

1. Identifies the strategies and techniques used by experienced walkers

The authors are with the School of Natural Resources and Environment, University of Michigan, Ann Arbor, MI.
2. Explores which of these strategies and techniques are associated with higher or lower levels of physical activity

3. Presents the Conceptual Content Cognitive Mapping $(3 \mathrm{CM})$ technique as a useful tool for investigating walking behavior.

Before providing a more detailed description of this research, it is useful to review the factors that have been found to influence physical activity participation.

\section{Individual Factors}

Knowledge of physical activity's benefits would seem to be an important factor in encouraging regular walking; however, there is very little evidence that successfully correlates one's knowledge about health benefits with adherence to a physical activity routine. ${ }^{8,9}$ These findings have led to speculation that knowledge about health benefits may only increase the chances one will initiate, rather than sustain, physical activity.

In contrast, motivation does seem to play a critical role in sustaining activity. Research indicates that individuals with stronger motivations related to obtaining personal health benefits are more likely to initiate and sustain a walking routine. ${ }^{10,11}$ There is also evidence which suggests that one's level of enjoyment of physical activity can be a significant factor for sticking with a 
physical activity routine, ${ }^{12-14}$ suggesting that the development of intrinsic motives may be particularly important.

\section{Social Factors}

Research has consistently indicated that social support is a significant factor in determining physical activity participation. $8,9,15$ This support seems to be effective whether offered directly by a significant other actually engaging in the activity ${ }^{16}$ or in more indirect ways, such as when one receives words of encouragement from a friend or family member. ${ }^{17}$

\section{Situational and Environmental Factors}

Numerous studies have identified lack of time as a major factor influencing physical activity participation. ${ }^{11,18-20}$ This issue may be especially prevalent for women and those with low socioeconomic status since they are likely to take on greater care-giving and family responsibilities. ${ }^{7}$

Attributes of the physical environments can also make it difficult to remain physically active. The most obvious example may be related to one's climate and geographic location. For example, evidence suggests that physical activity participation is lower in areas that experience more precipitation and greater fluctuations in temperature and humidity. ${ }^{21,22}$ Researchers investigating the role of the environment have also found that individuals are less active if they reside in neighborhoods which lack trails, sidewalks, and destinations. ${ }^{16,20,23,24}$ In addition, studies have highlighted the influence of safety related issues, such as automobile traffic ${ }^{25}$ and street lighting. ${ }^{23}$ Finally, research has shown that the aesthetic quality of the environment can impact physical activity participation, with factors such as the presence of natural features, ${ }^{16,26}$ attractive and interesting scenery ${ }^{27}$ and a variety of views ${ }^{28}$ all positively influencing activity levels.

Typically, recommendations designed to help individuals initiate and maintain a walking routine have focused on addressing these psychological, social, situational, and environmental factors by first establishing the benefits of being physically active, then encouraging individuals to set goals, develop a schedule, walk with a partner, and track their activity. While these strategies have been found to be useful in some cases, ${ }^{11,20,29-31}$ it is clear that many individuals still find it extremely difficult to sustain year-round walking routines.

One way to improve this situation is to seek advice from individuals who have been successful at maintaining a weekly walking routine. Initially, we might question the usefulness of advice from these experienced walkers since external conditions vary so widely from one individual to the next. It is certainly possible that experienced walkers live in areas more supportive of walking or have fewer constraints on their time. However, experienced walkers likely have faced considerable challenges themselves. There insights are worth investigating for a number of reasons. They have managed to cope effectively with barriers by using specific techniques. Knowing what these techniques are and which ones have been more effective may give us clues about what might work well for others. Furthermore, having access to walkable environments or fewer daily demands does not necessarily ensure that individuals will initiate and maintain an outdoor walking routine. Many individuals who do have the opportunity to use walkable settings fail to take advantage of them. Finding out more about what helps some individuals use these settings is, therefore, potentially useful. As a result, the primary goal of this research is to investigate the strategies that have proven most beneficial to experienced walkers.

\section{Methods}

\section{Participants}

Seventy-one adults from southeast Michigan were recruited by posting announcements in several local newspapers and community health bulletins. Eligible participants were at least 18 years of age and were required to have already been walking at least 3 days per week for at least 30 minutes per day. The study was reviewed by a university affiliated Institutional Review Board and deemed exempt from IRB oversight. Participants first completed the Conceptual Content Cognitive Mapping (3CM) exercise, described below. One week later they were mailed the survey instrument. Sixty-two participants $(\mathrm{n}=62)$ returned the survey instrument $(87 \%$ return rate). Survey respondents were predominately female, well-educated, married, and between 50-59 years old (see Table 1). Respondents, on average, indicated they had maintained a walking routine for almost 15 years and went on just over 6 walks per week, with each lasting approximately 44 minutes.

\section{Instruments}

Two different methods were used to investigate the strategies used by experienced walkers. One of these was a standard questionnaire-based instrument which investigated demographic information and participant walking behavior. The second method, the Conceptual Content Cognitive Mapping (3CM) exercise, has been used successfully to explore individuals' knowledge about a diverse number of issues, including hazardous waste facility placement, ${ }^{32}$ forest management practices, ${ }^{33}$ sustainable development, ${ }^{34}$ cancer treatment, ${ }^{35}$ pediatric pain assessment, ${ }^{36}$ and low-income housing, ${ }^{37}$ but has not previously been used to study physical activity participation. 
Table 1 Characteristics of Participants

\begin{tabular}{|c|c|}
\hline Characteristics & \\
\hline \multicolumn{2}{|l|}{ Gender $(\%)^{\mathrm{a}}$} \\
\hline Female & 89.8 \\
\hline Male & 8.5 \\
\hline \multicolumn{2}{|l|}{ Age $(\%)$} \\
\hline $20-29$ & 9.8 \\
\hline $30-39$ & 14.8 \\
\hline $40-49$ & 14.8 \\
\hline $50-59$ & 47.5 \\
\hline $60+$ & 13.1 \\
\hline \multicolumn{2}{|l|}{ Education $(\%)$} \\
\hline High school & 3.3 \\
\hline Some college & 19.7 \\
\hline 4-year degree & 42.6 \\
\hline Postgraduate degree & 34.4 \\
\hline \multicolumn{2}{|l|}{ Marital status (\%) } \\
\hline Single & 22.6 \\
\hline Married & 54.8 \\
\hline Divorced & 16.1 \\
\hline Widowed & 6.5 \\
\hline Number of years walking regularly (mean / median) & $14.8 / 10.0$ \\
\hline Number of walks taken each week (mean / median) & $6.6 / 5.0$ \\
\hline Duration (minutes) of each outing (mean / median) & $43.5 / 45.0$ \\
\hline
\end{tabular}

a The percentage of female and male participants is incomplete because several individuals did not indicate their gender on the survey instrument.

3CM. The 3CM was used to better understand the strategies experienced walkers used to sustain their routine. The $3 \mathrm{CM}$ is a card sorting exercise that reveals one's knowledge structure about a particular issue. ${ }^{38}$ The exercise begins by asking participants the following question:

"A lot of people say they have trouble sustaining a walking routine. If you were going to tell someone about what you have found helps you to walk regularly, what are all the things you would mention?"

Participants are then given a set of 45 pregenerated response cards and told to select all the responses they feel are appropriate or, if necessary, create new responses on blank cards. After participants finish selecting responses, they are asked to organize the cards into categories and then create descriptive names for each category they have created. The cards are then collected and the structure of the emergent categories is recorded. In this study, no 2 participants selected the exact same set of items or created the same categories. However, meaningful and cohesive categories are identified from across the participants' data using the latent partition analysis technique described below. Each 3CM interview lasted approximately 20 minutes.

Survey. A brief survey instrument was used both to further investigate the strategies participants used to sustain their walking routines and to validate the $3 \mathrm{CM}$ results. Similar to the $3 \mathrm{CM}$ task, participants were asked to think about what they would tell someone who wanted to know what has helped them to walk regularly. Participants then used a 5-point Likert scale to rate how likely they would be to mention different techniques, strategies, and motivations, such as setting a schedule, walking in nature, and preventing health problems. The techniques, strategies, and motivations included on the survey were identical to the 45 pregenerated $3 \mathrm{CM}$ responses (see Table 2).

The survey instrument was also used to assess demographic information and physical activity participation. Physical activity participation was investigated by asking participants to self-report the number of years they had walked regularly, the number of separate walks taken in a typical week, time spent walking during a typical outing, and amount of non-walking-related physical activity. 
Table 2 Techniques Recommended by Experienced Walkers (3CM)

\begin{tabular}{|c|c|}
\hline Category name and items included & Frequency item was mentioned \\
\hline \multicolumn{2}{|l|}{ Use health goals } \\
\hline Manage health & 44 \\
\hline Prevent health problems & 39 \\
\hline Manage your weight & 47 \\
\hline To be more energized & 35 \\
\hline Many personal benefits & 30 \\
\hline \multicolumn{2}{|l|}{ Use nearby nature } \\
\hline Walking in the woods & 18 \\
\hline Scenery & 28 \\
\hline Walking near water & 17 \\
\hline Quiet places & 18 \\
\hline Wildlife & 19 \\
\hline Nature & 26 \\
\hline Seasons & 18 \\
\hline Watch changes along route & 18 \\
\hline \multicolumn{2}{|l|}{ Mindful planning } \\
\hline Good walkways/paths & 33 \\
\hline Safe place & 18 \\
\hline Set a schedule & 31 \\
\hline Vary route & 28 \\
\hline Make part of routine/habit & 52 \\
\hline Don't overdo it & 13 \\
\hline Start slowly & 21 \\
\hline Monitor progress & 21 \\
\hline Identify obstacles/barriers & 7 \\
\hline Seeing other walkers & 13 \\
\hline Set goals (e.g., distance, time) & 31 \\
\hline Walking partner(s) & 35 \\
\hline Time with friends & 21 \\
\hline Walking group/club & 21 \\
\hline Do mental tasks while walking & 14 \\
\hline Walk pet & 13 \\
\hline Vary intensity & 13 \\
\hline Listen to music & 15 \\
\hline Prepare for bad weather & 18 \\
\hline Use devices & 20 \\
\hline Fit in with other activities & 21 \\
\hline Walk everywhere & 27 \\
\hline Right clothing/gear & 27 \\
\hline Make a priority & 38 \\
\hline
\end{tabular}




\section{Statistical Analyses}

The 3CM data were analyzed using latent partition analysis (LPA). Originally designed to analyze card sorting tasks, LPA is used to determine latent categories and intercategory relationships shared by a group regarding a particular issue. ${ }^{39}$ Once categories were identified they were given a short descriptive name to reflect the overall concept represented.

To validate the $3 \mathrm{CM}$ categories and identify a common set of themes, factor analysis was used to explore the 45 survey items measuring the strategies used to sustain a walking routine. Similar to latent partition analysis, factor analysis identified categories of items that have correlated response patterns. Principal-axis factoring with Varimax rotation was used. Factor structure was based on item loadings of at least .45, Eigenvalues greater than 1.0 and alpha coefficients of at least .55. Items loading on more than 1 factor above the .45 level were excluded. Once the categories were identified, each was given a short descriptive name and a mean score was calculated based on the average rating of items within each category, across all respondents. Paired-samples $t$ tests were then used to investigate differences between mean scores of each category. Finally, stepwise linear regression (stepping method criteria used probability of 0.05 for entry and 0.10 for removal) was used to explore the relationships among participants' self-reported physical activity and the factor analysis categories generated from the survey items that investigated the techniques, strategies, and motivations that participants rely on to sustain their walking routine.

\section{Results}

\section{CM}

Latent partition analysis identified 3 separate clusters of items (see Table 2). The first cluster, Use of health goals, was composed of items associated with motivations to avoid health problems and/or attain health benefits. The second cluster, Use nearby nature, was made up of items related to aesthetic and natural features of the walking environment. The final cluster, which was labeled Mindful planning, included a combination of items associated with how to maintain motivation/interest, set appropriate expectations, and cope with environmental and situational issues.

\section{Survey}

Factor analysis identified 8 distinct categories of strategies (the items composing each category appear underneath each category name in Table 3). Several of these categories closely complement the $3 \mathrm{CM}$ categories identified above. Interestingly, one category, Use nearby nature, contained exactly the same set of items as those included in the corresponding 3CM category. Likewise, the Use of health goals category, which emerged from both the 3CM and survey data, included a very similar set of items. Factor analysis of the survey data, however, split the Mindful planning category identified from the $3 \mathrm{CM}$ data into several smaller, more specific categories. One of these, also labeled Mindful planning, was in this instance composed of strategies associated specifically with maintaining and supporting motivation. These strategies ranged from more procedure-based advice for getting started, to the use of various extrinsic reinforcements. Items that grouped to form the Seek good routes category suggest the important role safety and the presence of quality walking paths play in determining whether one can maintain a walking routine. The next category, Use routines, emphasized the need to develop and stick with a plan for incorporating regular walking into one's normal schedule. Seek social support emerged as the sixth category, reflecting strategies which rely on the use of social motives and group support. Two single items, Prepare for bad weather and Walk pet also emerged as salient.

Of these categories, Seek good routes, Use health goals, and Prepare for bad weather were the strategies most frequently endorsed by survey respondents. Use routines received the next highest level of endorsement, followed closely by Use nearby nature, Mindful planning, and Seek social support. Walk pet received the lowest level of endorsement from the survey participants.

The regression analysis results indicated that individuals who were more likely to endorse the Seek social support strategy took significantly fewer walks per week (see Table 4). Seek social support also explained a significant proportion of the variance in the walks per week measure. This negative relationship was stronger among individuals who endorsed both the Seek social support and Seek good routes strategies. Together, these 2 strategies explained a significant proportion of the variance in the walks per week measure. Interestingly, participants who were more likely to endorse the Seek social support strategy also reported spending significantly more time participating in other types of physical activity besides walking. Seek social support also explained a significant proportion of the variance in the other types of physical activity measure.

\section{Discussion}

Taken together these results suggest that experienced walkers use a wide range of strategies and motives to sustain their walking routines. All of the categories that emerged from the factor analysis received at least a modest level of endorsement and no single category emerged as dominant. This finding lends some support to recent evidence suggesting that individuals with a greater number of exercise-related motives are also more likely to engage in physical activity. ${ }^{18}$ It is also worth noting, however, that 2 of the more highly endorsed categories (ie, Seek good routes, Use health goals) confirm the widely held belief that personal health concerns and the need for walkable environments are important factors associated with sustaining a walking routine..$^{10,40-43}$ 
Table 3 Techniques Recommended by Experienced Walkers (Survey)

\begin{tabular}{|c|c|c|c|}
\hline Category name and items included & Mean ${ }^{a}$ & SD & Alpha \\
\hline Seek good routes & $4.18^{\mathrm{a}}$ & .81 & .61 \\
\hline \multicolumn{4}{|l|}{ Good walkways/paths } \\
\hline \multicolumn{4}{|l|}{ Safe place } \\
\hline Use health goals & $4.17^{\mathrm{a}}$ & .82 & .86 \\
\hline \multicolumn{4}{|l|}{ Manage health } \\
\hline \multicolumn{4}{|l|}{ Prevent health problems } \\
\hline \multicolumn{4}{|l|}{ Manage your weight } \\
\hline \multicolumn{4}{|l|}{ To be more energized } \\
\hline \multicolumn{4}{|l|}{ Many personal benefits } \\
\hline \multicolumn{4}{|l|}{ Make priority } \\
\hline Use routines & $3.73^{b, c}$ & .84 & .55 \\
\hline \multicolumn{4}{|l|}{ Set a schedule } \\
\hline \multicolumn{4}{|l|}{ Do not vary route } \\
\hline \multicolumn{4}{|l|}{ Make part of routine/habit } \\
\hline Use nearby nature & $3.41^{\mathrm{b}, \mathrm{d}}$ & 1.01 & .93 \\
\hline \multicolumn{4}{|l|}{ Walking in the woods } \\
\hline \multicolumn{4}{|l|}{ Scenery } \\
\hline \multicolumn{4}{|l|}{ Walking near water } \\
\hline \multicolumn{4}{|l|}{ Quiet places } \\
\hline \multicolumn{4}{|l|}{ Wildlife } \\
\hline \multicolumn{4}{|l|}{ Nature } \\
\hline \multicolumn{4}{|l|}{ Seasons } \\
\hline \multicolumn{4}{|l|}{ Watch changes along route } \\
\hline Mindful planning & $3.14^{\mathrm{d}}$ & .97 & .86 \\
\hline \multicolumn{4}{|l|}{ Don't overdo it } \\
\hline \multicolumn{4}{|l|}{ Start slowly } \\
\hline \multicolumn{4}{|l|}{ Reward yourself } \\
\hline \multicolumn{4}{|l|}{ Monitor progress } \\
\hline \multicolumn{4}{|l|}{ Family support/encouragement } \\
\hline \multicolumn{4}{|l|}{ Identify obstacles/barriers } \\
\hline \multicolumn{4}{|l|}{ Seeing other walkers } \\
\hline \multicolumn{4}{|l|}{ Set goals (e.g., distance, time) } \\
\hline Seek social support & $3.12 \mathrm{~d}$ & 1.38 & .85 \\
\hline \multicolumn{4}{|l|}{ Walking partner(s) } \\
\hline Time with friends & & & \\
\hline Walking group/club & & & \\
\hline Prepare for bad weather & $3.90^{\mathrm{a}, \mathrm{c}}$ & 1.20 & - \\
\hline Walk pet & 2.51 & 1.57 & - \\
\hline
\end{tabular}

${ }^{a}$ Means are based on a 5-point rating scale with higher values denoting higher endorsement for the category. Means sharing a superscript are not significantly different from one another in a paired sample $t$ test at $P \leq .01$. 
Table 4 Stepwise Regression Models Predicting Number of Walks per Week and Amount of Nonwalking-Related Physical Activity per Week

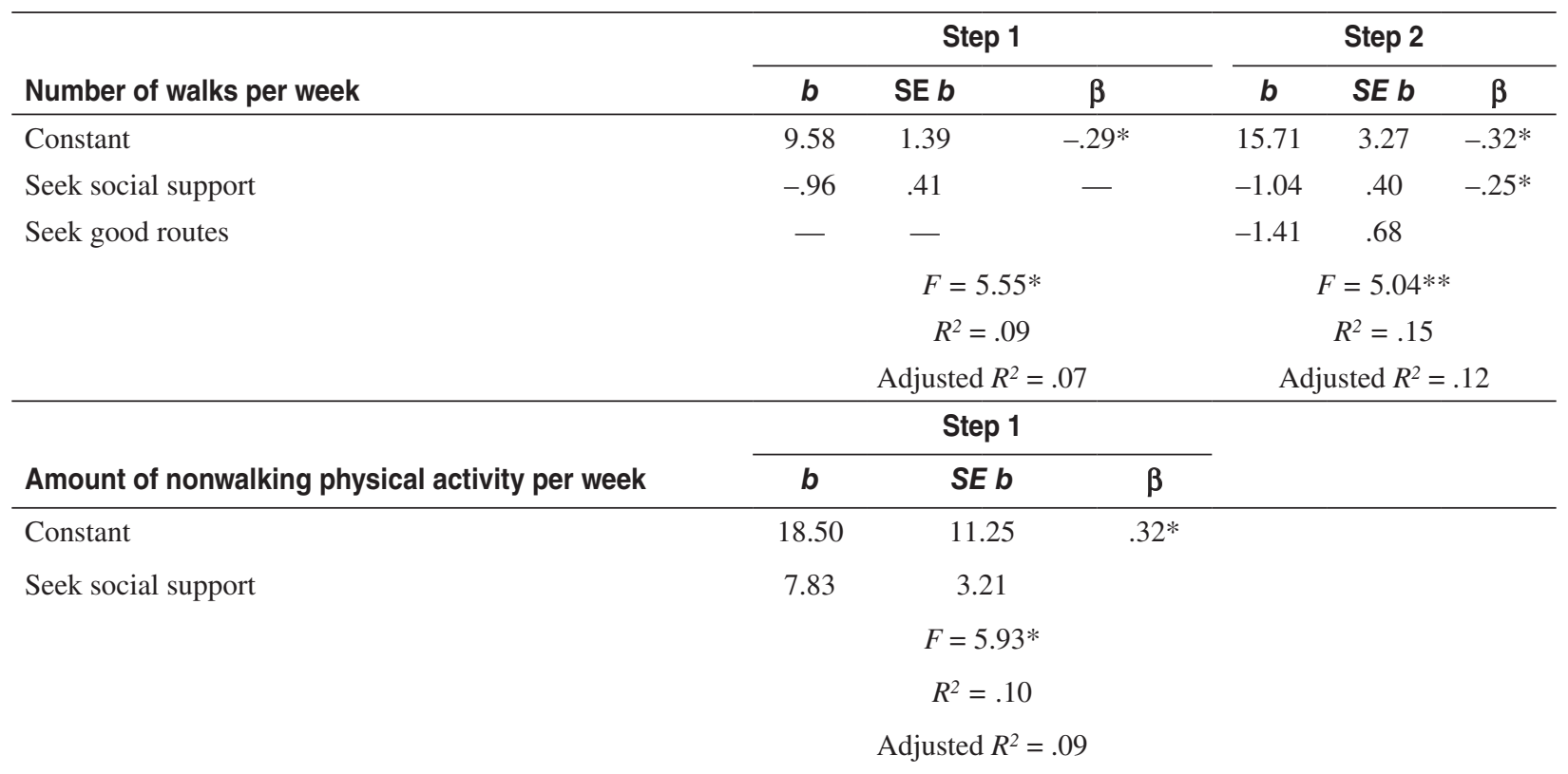

Note. $* P<.05 ; * * P \leq .01$.

Three categories of techniques (ie, Use routines, Use nearby nature, Mindful planning) illustrate the importance of being engaged and aware of the interaction between the external/physical environment and one's mental state. Routines, for instance, may owe much of their effectiveness to the fact that both structure and order are usually present in the external environment. As a result, the need for one to constantly reassess a situation is decreased and predictability is enhanced, reducing the demand on mental resources involved in planning and self-regulation. Indeed, once a routine has been developed, considerably less mental effort is needed to determine when, where, and how to walk, which in turn makes it easier to know what to expect before, during, and after the walk.

The use of nearby nature can also be explained in terms of this interaction. Physical environments, which include natural features such as trees, water, and animals, are a source of ready-made fascination for humans. ${ }^{44,45}$ What's more, arranging enough of these natural elements in the right way can greatly enhance the aesthetic quality of the environment. ${ }^{46}$ This combination of fascinating elements and aesthetic beauty may result in a more engaging and pleasant walking experience, increasing the chances one will continue to walk in the future.

Finally, the Mindful planning category suggests the importance of taking steps to manage expectations and maintain motivation. Experienced walkers seemed to recognize that feelings of frustration can often occur while one is struggling to adopt and stick with a routine and therefore recommend that individuals adopt a much gentler, more thoughtful approach. Experienced walkers also seemed to recommend a broad range of strategies for sustaining motivation, some involving material incentives and others focused on the achievement-based intrinsic satisfaction that results from successfully accomplishing a goal.

In addition, it is interesting that the strategy to Seek social support was not more highly endorsed given its popularity in interventions designed to encourage physical activity through the use of walking partners, groups, or clubs. In fact, those more likely to endorse the use of social support and good routes actually took fewer walks per week and were more likely to engage in nonwalking related physical activity. It is possible that this counterintuitive finding can be attributed to the fact that reliance on either or both techniques may actually psychologically limit the number of walking opportunities, creating a ceiling effect. This raises the possibility that while seeking social support and/or good routes are effective in promoting walking among those currently inactive, these same strategies may have reduced and even reversed effectiveness as one gains more walking experience. In the case of social support, walkers share the routine with others, possibly making it less likely they would walk alone or at unscheduled times. As a consequence, they may find themselves seeking out other types of physical activity. Likewise, requiring safe, quality walking routes may limit the number of settings deemed acceptable in one's community, thus reducing the number of walking opportunities. While this latter finding may seem obvious, it highlights the fact that one's perception of the walking environment is at least as important as objective measures of environmental quality. This suggests that efforts to 
alter individual perceptions of the outdoor environment should not be overlooked. Several studies, in fact, have found that efforts to enhance perceptions of the walking setting can have a marked positive impact. ${ }^{47,48}$

\section{Conclusion}

While these findings suggest that experienced walkers rely on a variety of different strategies to help them sustain their outdoor walking routines, they also indicate that strategies related to achieving positive health outcomes, utilizing attractive natural settings and developing realistic action plans are widely endorsed. There is reason to suspect that the effectiveness of some strategies, such as relying on social support, may diminish as one attempts to sustain an outdoor walking routine over the long-term.

Given the similarities between the Conceptual Content Cognitive Mapping (3CM) exercise and the survey results, this study also indicates that the $3 \mathrm{CM}$ technique can be a valuable method for exploring issues related to physical activity participation. This technique may be a particularly useful way for health practitioners to understand how individuals conceptualize the barriers and motivations associated with physical activity.

\section{Acknowledgments}

The authors would like to thank Kimberly Wolske and Melissa Hopkins for assisting in data collection and Nicole Premo for assistance in preparing the manuscript. This research was partially funded by a McIntire-Stennis grant from the Ecosystem Management Initiative, School of Natural Resource and Environment, University of Michigan.

\section{References}

1. CDC. Prevalence of self-reported physically active adults-United States, 2007. MMWR. 2008;57(48):12971300. PubMed

2. Finkelstein EA, Fiebelkorn IC, Wang G. State-level estimates of annual medical expenditures attributable to obesity. Obes Res. 2004;12:18-24. PubMed doi:10.1038/ oby.2004.4

3. Barnes P. Physical activity among adults: United States, 2000 and 2005. http://www.cdc.gov/nchs/products/ pubs/pubd/hestats/physicalactivity/physicalactivity.htm. Accessed July 1, 2009.

4. CDC. Adult participation in recommended levels of physical activity-United States, 2001 and 2003. MMWR. 2005;54(47):1208-1212. PubMed

5. US Department of Health and Human Services. Physical activity and health: a report of the Surgeon General. Atlanta, GA: U. S. Department of Health and Human Services; 1996.

6. Morgan WP, Dishman RK. Adherence to exercise and physical activity. Quest. 2001;53:277-278. doi:10.1080/ 00336297.2001.10491744

7. Seefeldt V, Malina RM, Clark MA. Factors affecting levels of physical activity in adults. Sports Med. 2002;32(3):143168. PubMed doi:10.2165/00007256-200232030-00001
8. Bauman A, Sallis JF, Dzewaltowski DA, Owen N. Toward a better understanding of the influences on physical activity: The role of determinants, correlates, causal variables, mediators, moderators, and confounders. Am J Prev Med. 2002;23(2S):5-14. PubMed doi:10.1016/S07493797(02)00469-5

9. Dishman RK, Sallis JF, Orenstein DR. The determinants of physical activity and exercise. Public Health Rep. 1985;100(2):158-171. PubMed

10. Hirvensalo M, Lampinen P, Rantanen T. Physical exercise in old age: An eight-year follow-up study on involvement, motives, and obstacles among persons age 65-84. J Aging Phys Act. 1998;6:157-168.

11. Nies MA, Motyka CL. Factors contributing to women's ability to maintain a walking program. J Holist Nurs. 2006;24(1):7-14. PubMed doi:10.1177/0898010105282520

12. Ingledew DK, Markland D, Medley AR. Exercise motives and stages of change. J Health Psychol. 1998;3:477-489. PubMed doi:10.1177/135910539800300403

13. Maltby J, Day L. The relationship between exercise motives and psychological well-being. J Psychol. 2001;135(6):651660. PubMed doi:10.1080/00223980109603726

14. Wankel LM. The importance of enjoyment to adherence and psychological benefits from physical activity. Int $J$ Sport Psychol. 1993;24:151-169.

15. Trost SG, Owen N, Bauman A, Sallis J, Brown W. Correlates of adults' participation in physical activity: Review and update. Med Sci Sports Exerc. 2002;34(12):19962001. PubMed doi:10.1097/00005768-200212000-00020

16. Giles-Corti B, Donovan RJ. Relative influences of individual, social environmental, and physical environmental correlates of walking. Am J Public Health. 2003;93(9):15831589. PubMed doi:10.2105/AJPH.93.9.1583

17. Booth ML, Owen N, Bauman A, Clavisi O, Leslie E. Social-cognitive and perceived environmental influences associated with physical activity in older Australians. Prev Med. 2000;31:15-22. PubMed doi:10.1006/ pmed.2000.0661

18. Anderson CB. When more is better: Number of motives and reasons for quitting as correlates of physical activity in women. Health Educ Res. 2003;18(5):525-537. PubMed doi:10.1093/her/cyf041

19. Dunton GF, Schneider M. Perceived barriers to walking for physical activity. Prev Chronic Dis. 2006;3(4):1-11. PubMed

20. Eyler AA, Brownson RC, Bacak SJ, Housemann RA. The epidemiology of walking for physical activity in the United States. Med Sci Sports Exerc. 2003;35(9):1529-1536. PubMed doi:10.1249/01.MSS.0000084622.39122.0C

21. Humpel N, Owen N, Iverson D, Leslie E, Bauman A. Perceived environment attributes, residential location, and walking for particular purposes. Am J Prev Med. 2004;26(2):119-125. PubMed doi:10.1016/j. amepre.2003.10.005

22. Merrill RM, Shields EC, White GL, Druce D. Climate conditions and physical activity in the United States. Am J Health Behav. 2005;29(4):371-381. PubMed doi:10.5993/ AJHB.29.4.9

23. Addy CL, Wilson DK, Kirtland KA, Ainsworth BE, Sharpe P, Kimsey D. Associations of perceived social and physical environmental supports with physical activity and walking behavior. Am J Public Health. 2004;94(3):440-443. PubMed doi:10.2105/AJPH.94.3.440 
24. Moudon AV, Lee C, Cheadle AD, et al. Attributes of environments supporting walking. Am J Health Promot. 2007;21:448-459. PubMed doi:10.4278/0890-117121.5.448

25. Troped PJ, Saunders RP, Pate RR, Reininger B, Addy CL. Correlates of recreational and transportation physical activity among adults in a New England community. Prev Med. 2003;37:304-310. PubMed doi:10.1016/S00917435(03)00137-3

26. Brown BB, Werner CM, Amburgey JW, Szalay C. Walkable route perceptions and physical features. Environ Behav. 2007;39(1):34-61. doi:10.1177/0013916506295569

27. Spence JC, Plotnikoff RC, Rovniak LS, Ginis K, Rodgers W, Lear SA. Perceived neighborhood correlates of walking among participants visiting the Canada on the Move website. Can J Public Health. 2006;97(S1):S36-S44. PubMed

28. McCormack G, Giles-Corti B, Lange A, Smith T, Martin K, Pikora T. An update of recent evidence of the relationship between objective and self-report measures of the physical environment and physical activity behaviors. $J$ Sci Med Sport. 2004;7(1S):81-92. PubMed doi:10.1016/ S1440-2440(04)80282-2

29. Aittasalo M, Miilunpalo S, Kukkonen-Harjula K, Pasanen M. A randomized intervention of physical activity promotion and patient self-monitoring in primary health care. Prev Med. 2006;42:40-46. PubMed doi:10.1016/j. ypmed.2005.10.003

30. Dishman RK, DeJoy DM, Wilson MG, Vandenberg RJ. Move to improve: a randomized workplace trial to increase physical activity. Am J Prev Med. 2009;36(2):133-141. PubMed doi:10.1016/j.amepre.2008.09.038

31. Shilts MK, Horowitz M, Townsend MS. Goal setting as a strategy for dietary and physical activity behavior change: A review of the literature. Am J Health Promot. 2004;19(2):81-93. PubMed doi:10.4278/0890-117119.2.81

32. Austin DE. Exploring perceptions of hazardous waste facility proposals in Indian country: an application of the active symbol cognitive map model. Ann Arbor, MI: University of Michigan; 1994.

33. Kearney AR, Bradley G, Kaplan R, Kaplan S. Stakeholder perspectives on appropriate forest management in the pacific northwest. For Sci. 1998;45(1):62-73.

34. Byrch C, Kearins K, Milne M, Morgan R. Sustainable "what"? A cognitive approach to understanding sustainable development. Qual Res Account Manag. 2007;4(1):26-52. doi:10.1108/11766090710732497
35. Lehto RH. Worry and cognitive representations of illness in cancer. Ann Arbor: University of Michigan; 2004.

36. Van Hulle Vincent C. Nurses' perceptions of children's pain: a pilot study of cognitive representations. J Pain Symptom Manage. 2007;33(3):290-301. PubMed doi:10.1016/j.jpainsymman.2006.08.008

37. Wells NM. Our housing, our selves: a longitudinal investigation of low-income women's participatory housing experiences. J Environ Psychol. 2005;25:189-206. doi:10.1016/j.jenvp.2005.02.002

38. Kearney AR, Kaplan S. Toward a methodology for the measurement of knowledge structures of ordinary people: the Conceptual Content Cognitive Map (3CM). Environ Behav 1997;29(5):579-617. doi:10.1177/0013916597295001

39. Miller DM, Wiley DE, Wolfe RG. Categorization methodology: an approach to the collection and analysis of certain classes of qualitative information. Multivariate Behav Res. 1986;21(2):135-167. doi:10.1207/s15327906mbr2102_1

40. Frank LD, Engelke PO, Schmid TL. Health and community design: the impact of the built environment on physical activity. Washington: Island Press; 2003.

41. Gill K, Overdorf V. Incentives for exercise in younger and older women. J Sport Behav. 1994;17(2):87-97.

42. Owen N, Humpel N, Leslie E, Bauman A, Sallis JF. Understanding environmental influences on walking: review and research agenda. Am J Prev Med. 2004;27(1):67-76. PubMed doi:10.1016/j.amepre.2004.03.006

43. Puretz SL, Haas A, Meltzer D. Profile of exercising women. Percept Mot Skills. 1996;82:890. PubMed doi:10.2466/pms.1996.82.3.890

44. James W. Psychology: the briefer course. New York: Harper; 1892.

45. Kaplan S. The restorative benefits of nature: toward an integrative framework. J Environ Psychol. 1995;15:169-182. doi:10.1016/0272-4944(95)90001-2

46. Kaplan S. Aesthetics, affect, and cognition: environmental preference from an evolutionary perspective. Environ Behav. 1987;19(1):3-32. doi:10.1177/0013916587191001

47. Duvall J. Deliberate engagement as a strategy for promoting behavior change while enhancing well-being. Ann Arbor: University of Michigan; 2010.

48. Humpel N, Marshall AL, Leslie E, Bauman A, Owen $\mathrm{N}$. Changes in neighborhood walking are related to changes in perceptions of environmental attributes. Ann Behav Med. 2004:27(1):60-67. PubMed doi:10.1207/ s15324796abm2701_8 